\title{
Lesitin İçeren Antibiyotik Kilit Çözeltilerinin Klebsiella pneumoniae Biyofilmi Üzerine in vitro Etkileri
}

\author{
Emel MATARACI KARA ${ }^{1}$, Berna ÖZBEK ÇELİK ${ }^{1}$
}

ÖZ

Amaç: Gram negatif, genellikle kapsüllü, hareketsiz, sporsuz, çomak şeklinde bir bakteri olan Klebsiella pneumoniae günümüzde toplum ve hastane kökenli enfeksiyonların önemli etkenlerinden biridir. Bu bakteri kateter yüzeyinde bir mikrobiyal biyofilm oluşturarak kateter ilişkili enfeksiyonlara neden olabilmektedir. Kateter ilişkili enfeksiyonların tedavisinde en etkili tedavi yöntemi enfekte kateteri çıkarmak ve sistemik antibiyotik tedavisine başlamak olsa da bu işlem hastanın sağlık durumu ile ilgili nedenlerle her zaman yapılamamaktadır. Enfekte kateterin çıkartılamadığı hastalarda sistemik antimikrobiyal tedavi ile birlikte yardımcı bir tedavi seçeneği olarak antibiyotik kilit (AK) tedavisi kullanılması Infectious Diseases Society of America ve Centers for Disease Control and Prevention gibi sağlik kuruluşları tarafindan önerilmektedir.

Gereç ve Yöntemler: Çalışmamızda, in vitro yöntemle santral venöz kateter (SVK) modeli oluşturularak biyofilm oluşturduğu tespit edilen iki SVK ilişkili bakteriyemi enfeksiyon etkeni Klebsiella pneumoniae suşuna karşı bir yüzey aktif ajan olan lesitinin tek başına ve çeşitli antibiyotiklerle kombinasyonlarının 96 saatlik etkisi araştııılmıştır.

Bulgular: Çalışmamızdan elde ettiğimiz sonuçlara göre, lesitin+tobramisin ve lesitin+doripenem kombinasyonlarını içeren AK çözeltisinin her iki suş içinde en az 2- $\log _{10}$ 'luk bir artış sağlayarak biyofilme gömülmüş suşlar üzerinde antagonist etki oluşturduğu, lesitin+kolistin, lesitin+tigesiklin ve lesitin+siprofloksasin içeren AK çözeltilerinin ise her iki suşa ait kateter biyofilm modelinde antibiyotiklerin tek başına oluşturduğu etkiden daha az etki gösterdiği saptanmıştır.

Sonuç: Çalışmamızda lesitin+tobramisin ve lesitin+doripenem kombinasyonlarının antagonist etki göstermesi günlük hayatta tükettiğimiz pek çok üründe gıda takviyesi olarak bulunan lesitinin enfeksiyon hastalıklarının tedavisindeki etkilerinin ortaya koyulması açısından önemli olduğu düşüncesindeyiz.

Anahtar Kelimeler: Kateter enfeksiyonları; biyofilm; antibiyotik kilit tedavisi; lesitin; Klebsiella pneumoniae.

\section{In vitro Effectiveness of Lecithin-Containing Antibiotic Lock Solutions on Klebsiella pneumoniae Biofilms}

\begin{abstract}
Aim: Klebsiella pneumoniae which is a gram negative, generally capsulated, non-moving, non-sporing bacteria, nowadays to be an important cause of community-acquired and nosocomial infection. These bacteria can cause catheter related infections by forming biofilm on the surface of catheter. The most effective treatment method of catheter related infection is to remove infectious catheter and start systemic antibiotic treatment but this process can't be practiced in all cases due to the patients' health conditions. Infectious Diseases Society of America and Centers for Disease Control and Prevention suggest that systemic antibiotic therapy together with antibiotic lock therapy (ALT), as an adjuvant therapy, for patients whose infectious catheter can't be removed.

Material and Methods: In our study, the in vitro efficacy of several antibiotics alone or in combination with lecithin which is a surface active agent, as a 96 hour lock solution on in vitro CVC biofilm model against two biofilm-embedded catheter related bacteremia infection agents Klebsiella pneumoniae strains were investigated.
\end{abstract}

1 İstanbul Üniversitesi, Eczacılık Fakültesi, Farmasötik Mikrobiyoloji AD, İstanbul, Türkiye 
Results: According to our results, ALT solutions containing lecithin+tobramycin and lecithin+doripenem combinations had an antagonist effect on the biofilmembedded strains by increasing at least $2-\log _{10}$ in both strains and ALT solutions containing lecithin+colistin, lecithin+tigecycline and lecithin+ciprofloxacin had less effect than antibiotics alone on the biofilm-embedded strains.

Conclusion: In our study, we believe that because lecithin+tobramycin and lecithin+doripenem combinations showed antagonist activity, the usage of lecithin in daily life as a nutritional supplement will be a guide for clinicians.

Keywords: Catheter infections; biofilm; antimicrobial lock therapy; lecithin; Klebsiella pneumoniae.

\section{Gíiș}

Modern tıp uygulamalarının artık vazgeçilmez araçlarından olan kateterler cinslerine ve uygulandıkları yerlere göre birkaç günden bir yıla kadar uzanabilen değişik sürelerde hastalarda tutulabilirler. Ancak bu uygulamaların en önemli dezavantajları katetere bağlı enfeksiyonlar olarak karşımıza çıkmaktadır $(1,2)$. Kateter ilişkili enfeksiyonlar kateter yüzeyinde mikrobiyal bir biyofilmin gelişmesiyle oluşurlar. Tedavilerinde sıklıkla karşılaşılan başarısızlık bu enfeksiyonları kompleks ve zor hale getirmektedir. Biyofilm enfeksiyonu etkeni mikroorganizmaları öldürmek için yaklaşık > 100-1000 kat daha fazla antimikrobiyal madde gerekli olmaktadır (1,3). Kullanım süresi boyunca katetere bağlı olarak gelişen enfeksiyonlar, hastaların hastanede kalış sürelerini, hastane maliyetlerini, mortalite ve morbidite oranını artırmaktadır (4). Kateter ile ilișkili enfeksiyonlar için risk faktörleri hastanenin tipi ve büyüklüğüne, ünitenin tipine, kateterin uygulama bölgesine, kateterin kalış süresine, kateter bakım işlemlerine, personelin eğitimine, hastanın altta yatan hastalığına göre değişebilir $(4,5)$. Özellikle yoğun bakım ve immunsuprese hastalarda olmak üzere kateter ile ilişkili gelişen bakteriyemilerde mortalite oranı \%12-25 arasindadır (6). Bu nedenle mortalite ve maliyeti bu kadar yüksek olan bir enfeksiyonun gelişmeden önlenmesi çok önemlidir. Bu durumda en etkili yöntem infekte kateteri çıkarmak olsa da bu işlem hastanın durumu, teknik nedenler ve maliyetin yükselmesi nedeniyle her zaman yapılamamaktadır. İnfekte kateterin çıkartılması yerine uygulanan antibiyotik kilit (AK) tekniğinde yüksek konsantrasyon antibiyotik solüsyonu merkezi venöz kateter içine verilerek saatler yada günlerce tutulması sağlanır (2,7). Antibiyotik kilit solüsyonunun içeriği, biyofilm oluşturan mikroorganizmaya, bu mikroorganizmanın özelliklerine, kullanılan antimikrobiyal ajanın farmakodinamiğine bağlı olarak değişmektedir (4).

Kateter ilişkili enfeksiyonlara sıklıkla Staphyloccocus aureus, koagülaz negatif Staphyloccus, Candida spp. türlerinin neden olduğu bilinmekle birlikte başta Enterobacteriaceae ailesi olmak üzere dirençli Gram negatif mikroorganizmalara da rastlanmakta ve göstermiş oldukları çoklu ilaç direnci nedeniyle de bu enfeksiyonlar artan mortalite ile sonuçlanmaktadır (8).

Lesitin, fosfolipit bazlı doğal bir yüzey aktif madde olup, ilaç ve gıda sanayinde yaygın olarak kullanılmaktadır.
Bunun yanı sıra antiseptik ve dezenfektan maddelerin mikrobiyolojik analizi için antiseptik/dezenfektan maddeyi nötralize edici ajan olarak kullanımı da kılavuzlarda önerilmektedir (6,9-11). Lesitinle yapılan kısıtlı çalışmalardan elde edilen sonuçlar $(12,13)$, lesitinin kateter yüzeyine hidrofilik yapı kazandırarak bakterinin kateter yüzeyine bağlanmasını engelleyebileceğini ortaya koymaktadır. Bu nedenle çalışmamızda, in vitro damar içi kateter enfeksiyon modeli oluşturularak biyofilm oluşturduğu tespit edilen kateter ilişkili bakteriyemi enfeksiyon etkeni olarak klinikten izole edilmiş iki $K$. pneumoniae suşuna karşı yüzey aktif ajan özelliği nedeniyle AK çözeltisi olarak ilk kez denenecek olan lesitinin tek başına ve çeşitli antibiyotiklerle kombinasyonlarının in vitro etkinliği araştırılmıştır.

\section{GEREÇ VE YÖNTEMLER}

Bakteri: Çalışmamızda kullanılan suşların antibiyotik duyarlılığının belirlendiği çalışmalarda Escherichia coli ATCC 25922; suşların biyofilm oluşumu yönünden incelendiği deneylerde ise K. pneumoniae ATCC 700603 standart suşu kullanılmıştır (14). Lesitinin tek başına ve çeşitli antibiyotiklerle kombinasyon halinde AK çözeltisi olarak denendiği koşullarda ise İstanbul Medipol Üniversitesi Tıp Fakültesi Enfeksiyon Hastalıkları ve Klinik Mikrobiyoloji Anabilim Dalı laboratuvarlarında kateter ilişkili bakteriyemi enfeksiyon etkeni olarak klinikten izole edilen iki adet $K$. pneumoniae (KP-1 ve KP-2) suşu kullanılmıştır. Suşların biyofilm oluşumu standart mikroplak metodu kullanılarak kristal viyole boyamayla tespit edilmiş ve güçlü biyofilm oluşturdukları görüldügüünden deneylerde kullanımlarına karar verilmiştir (15).

Antibiyotik Duyarlılık Deneyleri: Çalışmamızda kullanılan bakteri suşlarının planktonik formlarına ait minimal inhibitör konsantrasyon (MIK) değerleri EUCAST'1n mikrodilusyon metodu kullanılarak belirlenmiştır (14).

Antibiyotik kilit modeli: 7-French 3 lümenli silikon santral venöz kateterler (Cook, Inc., Bloomington, IN, ABD) aseptik şartlarda 1'er cm kesilmiş ve biyofilm oluşumu için 106 koloni oluşturan birim/ml bakteri süspansiyonu içeren TSB içerisinde $37^{\circ} \mathrm{C}$ 'de 24 saat inkübe edilmiştir. Ardından segmentler bakteri ortamından alınarak üzerindeki sıv1 silkelenmiştir. Biyofilm oluşturulan segmentlerden 3'er adet alınarak 10 kez 1'er ml PBS ile planktonik bakterilerin uzaklaştırılması amacıyla yıkanmış, ardından 10 dakika boyunca $20 \mathrm{kHz}$ frekansinda sonikasyona (Bandelin Sonopuls HD 2070 Homojenizatör, Bandelin Elektronik $\mathrm{GmbH \& Co.} \mathrm{KG)} \mathrm{tabii} \mathrm{tutulmuş,} \mathrm{sonrasında} \mathrm{ise} 30$ saniye boyunca vortekslenmiştir. Çalışmamızda, kolistin, doripenem, tigesiklin, siprofloksasin ve tobramisin $400 \mathrm{x}$ MİK konsantrasyonunda, yüzey aktif bir ajan olan lesitin ise kılavuzların önerdiği \%0,3'lük konsantrasyonu sağlayacak şekilde Triptik soy buyyonunda hazırlanarak deneylerde kullanılmışlardır (5,9). Kontrol olarak antibiyotiksiz steril PBS çözeltisi tüm deney boyunca çalışmada kullanılmıştır. Her koşul için 3'er kateter segmenti 24., 48., 72. ve 96. saat aşağıdaki belirtilen AK çözeltilerine temas ettirilmişlerdir: lesitin (\%0,3, Sigma), kolistin sulfat (KP-1, $50 \mathrm{mg} / \mathrm{L}$; KP-2, $24 \mathrm{mg} / \mathrm{L}$; Koçak Farma A.Ş.) doripenem (KP-1, $100 \mathrm{mg} / \mathrm{L}$; KP-2, 200 
mg/L; Johnson \& Johnson Inc.), tigesiklin (KP-1, 24 mg/L; KP-2, 800 mg/L; Pfizer İlaç A.Ş.), siprofloksasin (KP-1, 800 mg/L; KP-2, 100 mg/L; Bayer İlaç A.Ş.), tobramisin (KP-1, $12800 \mathrm{mg} / \mathrm{L}$; KP-2, $200 \mathrm{mg} / \mathrm{L}$; Nobel İlaç A.Ş.) tek başına, ve aynı konsantrasyonları sağlayacak şekilde lesitin + kolistin, lesitin + doripenem, lesitin + tigesiklin, lesitin + siprofloksasin, lesitin + tobramisin. İnkübasyon süresinin sonunda gerekli seyreltmeler yapılarak TSA içeren steril Petri kutularına $100 \mu 1$ ekimler yapılmış, Petriler $37^{\circ} \mathrm{C}$ 'lik etüvde bir gece bekletilmiştir (tespit limiti; > $10 \mathrm{kob} / \mathrm{ml}$ ). Elde edilen değerler zaman " $\mathrm{x}$ " ekseninde, bakteri sayısının logaritmik değeri "y" ekseninde olacak şekilde gösterilerek zaman-ölüm eğrileri çizilmiş, sonuçlar NCCLS verilerine göre aşağıdaki şekilde yorumlanmıştır (16):

a) Sinerjist etki: Antibiyotiklerin 24. saatte kombinasyon halinde oluşturduğu etki sonucu elde edilen bakteri sayısının, kombinasyonda bulunan antibiyotiklerden daha aktif olanın tek başına oluşturduğu etki sonucu elde edilen bakteri sayısına göre 100 kat ya da daha fazla $(\geq 2$ $\log _{10}$ ) azalmış olması sinerjist etki olarak kabul edilmiştir. b) Additif etki: Antibiyotiklerin 24. saatte kombinasyon halinde oluşturduğu etki sonucu elde edilen bakteri sayısının, kombinasyonda bulunan antibiyotiklerden daha aktif olanın tek başına oluşturduğu etki sonucu elde edilen bakteri sayısına göre $<10$ kat $\left(1 \log _{10}\right)$ azalmış ya da artmış olması additif etki olarak kabul edilmiştir

c) Antagonist etki: Antibiyotiklerin 24. saatte kombinasyon halinde oluşturduğu etki sonucu elde edilen bakteri sayısının, kombinasyonda bulunan antibiyotiklerden daha aktif olanın tek başına oluşturduğu etki sonucu elde edilen bakteri sayısına göre 100 kat ya da daha fazla $\left(\geq 2 \log _{10}\right.$ ) artmış olması antagonist etki olarak kabul edilmiştir. Antibiyotiklerin tek başlarına ve lesitin ile kombinasyon halinde göstermiş oldukları $\geq 3$ $\log _{10}$ 'luk azalma ise NCCLS verilerine göre bakterisidal etki olarak yorumlanmıştır (16).

\section{İstatistiksel Analiz}

Çalışma boyunca tüm deneyler $3 \mathrm{kez}$ tekrar edilmiş ve elde edilen sonuçlar One-way ANOVA ile Bonferroni'nin çoklu karşılaştırma testi kullanılarak (GraphPad Software Inc., San Diego, CA, ABD) P değeri<0,05 olarak kabul edilip yorumlanmıştır.

\section{BULGULAR}

Çalışmada kullanılan antibiyotiklere ait MİK değerleri Tablo 1'de gösterilmiştir. MIK sonuçlarından elde ettiğimiz bulgulara göre, KP-1, kolistin, tigesiklin, doripeneme duyarl1, siprofloksasin ve tobramisine dirençli; KP-2, kolistin, doripenem, tobramisin ve siprofloksasine duyarlı, tigesikline ise orta duyarlı olarak tespit edilmiştir. Lesitin yüzey aktif ajan özelliğinden çalışmaya dahil edildiğinden ve antimikrobiyal özellik içermediğinden tüm deney boyunca kılavuzların antimikrobiyal maddenin nötralizasyonu için önerdiği $\% 0,3$ konsantrasyonunda kullanılmıştır $(6,9,11)$.

AK tekniğinin çalışmalarından elde edilen sonuçlara göre, tobramisin ve doripenemin her iki bakteriye karş1 denenen tüm koşullarda biyofilmdeki bakteri sayısında > $5 \log _{10}$ azalma sağlayarak kuvvetli bakterisidal etki gösterdikleri tespit edilmiş ve istatistiksel açıdan anlamlı bulunmuştur (Şekil 1) (P<0,05). Siprofloksasine dirençli olan KP-1 suşunda siprofloksasinin tek başına denendiği koşullarda $>5 \log _{10}$ azalma sağlayarak kuvvetli bakterisidal etki gösterdiği görülürken, siprofloksasine duyarlı olan KP-2 suşunda ise siprofloksasinin tek başına biyofilmdeki bakteri sayısında yaklaşık $2 \log _{10}$ azalma sağlayabildiği tespit edilmiştir. Siprofloksasinin tek başına KP-2 suşu için biyofilmdeki bakteri sayısında yapmış olduğu bu $2 \log _{10}$ 'luk azalma ise istatistiksel açıdan anlamlı bulunamamıştır. Tigesiklinin tek başına denendiği tüm koşullarda ise biyofilmdeki bakteri sayısında $>3 \log _{10}$ azalma sağlayarak bakterisidal etki gösterdiği görülmüştür. Kolistinin 400 x MIK konsantasyonda tek başına AK çözeltisi olarak denendiği koşullarda ise her iki suşa ait biyofilmde de 48. saatte canlı bakteri sayısında önemli bir azalmaya neden olduğu, ancak 72. saatte biyofilmdeki hücrelerde tekrar üremenin olduğu saptanmış ve istatistiksel açıdan anlamlı bulunmuştur $(\mathrm{P}<0,05)$.

Tablo 1. Antibiyotiklerin Klebsiella pneumoniae suşlarına karşı saptanan MİK değerleri

\begin{tabular}{|c|c|c|c|c|c|}
\hline \multirow{2}{*}{ Mikroorganizma } & \multicolumn{5}{|c|}{ MIK (mg/L) } \\
\cline { 2 - 6 } & CIP & TOB & DOR & TGC & CS \\
\hline KP-1 & 2 & 32 & 0,25 & 0,06 & 0,125 \\
\hline KP-2 & 0,25 & 0,5 & 0,5 & 2 & 0,06 \\
\hline
\end{tabular}

CIP:Siprofloksasin, TOB: Tobramisin, DOR: Doripenem, TGC: Tigesiklin, CS: Kolistin, MİK: Minimal İnhibitör Konsantrasyon, mg/L: milligram/litre, KP-1: Klebsiella pneumoniae-1, KP-2: Klebsiella pneumoniae-2.

Çalışmamızdan elde ettiğimiz bulgulara göre, lesitinin tek başına \%0,3 konsantrasyonda denendiği koşullarda biyofilmdeki bakteri sayısında kontrolle kıyaslandığında anlamlı bir fark yaratamadığı tespit edilmiştir. Lesitinin tobramisin ve doripenemle olan kombinasyonlarında, çalışmamızda kullanılan her iki suşa ait biyofilmde 96 . saatte canlı bakteri sayısında $>2 \log _{10}$ artış sağlayarak antagonist etki gösterdiği tespit edilmiştir. Lesitinin kolistin, siprofloksasin ve tigesiklin ile olan kombinasyonlarında ise antibiyotiklerin tek başına olan etkisiyle karşılaştırıldığında biyofilmdeki bakteri sayısında artışa neden olduğu görülmüştür (Şekil 1).

\section{TARTIŞMA}

Günümüzde, SVK'ların hasta bakımında yaygın bir şekilde kullanılmasına paralel olarak kateter ilişkili enfeksiyonlarda da ciddi bir artışın gözlenmesi endişe yaratmaktadır. Gelişen SVK enfeksiyonları hem hastanede yatış süresini uzatmakta hem de hasta başı maliyeti önemli oranda arttırmaktadır. ABD'de her y1l yaklaşık 75,000 kateter ilişkili enfeksiyon meydana gelmekte ve bu tedavileri için 300 milyon ile 2,3 milyar dolar arasında değişen ek harcama yapılmaktadır (1). Özellikle yoğun bakım ve immün baskılanmış hastalarda kateter ilişkili bakteriyemi mortalite oranı \%12-25 arasındadır $(1,2,17,18)$. Mikroorganizmaların SVK'ların hem iç hem de diş yüzeyinde kolonize olabilmesiyle gelişen mikrobiyal biyofilmlerin tedavisinde Amerika Enfeksiyon Hastalıkları Derneği (IDSA-Infectious Diseases Society of America) ve Amerika Birleşik 


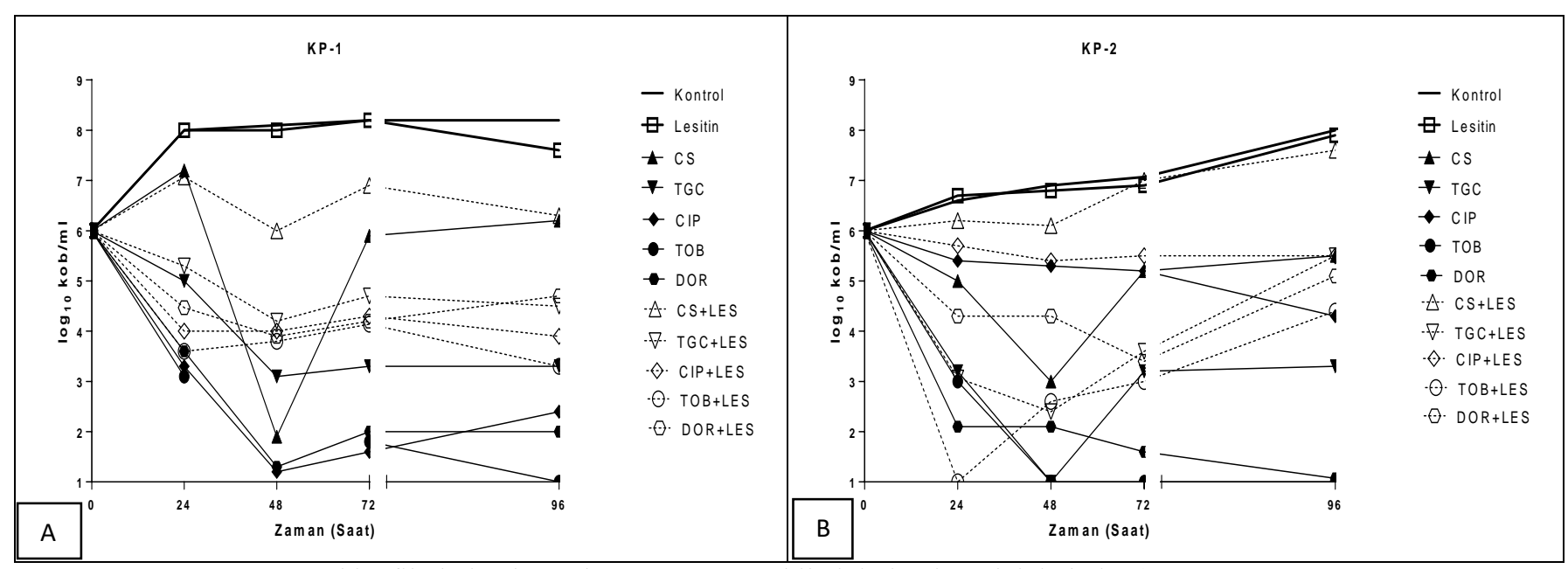

Şekil 1. K. pneumoniae biyofilmlerine karşı denenen AK çözeltilerinin in vitro aktiviteleri: A) KP-1, B) KP-2. (Kolistin (CS), Tigesiklin (TGC), Siprofloksasin (CIP), Tobramisin (TOB), Doripenem (DOR), Lesitin (LES))

Devletleri Hastalık Kontrol ve Korunma Merkezleri (CDC-Centers for Disease Control and Prevention) antibiyotik kilit tedavisini önermektedir $(1,4)$.

Biyofilmlerin tüm mikrobiyolojik enfeksiyonların \% 60'ından fazlasının nedeni olduğu tahmin edilmektedir (1). Biyofilmlere karşı antiseptik, dezenfektan vb. gibi pek çok maddenin etkinliğinin araştırıldığı çalışmalar dünya çapında yayınlanmaktadır. $\mathrm{Bu}$ çalışmaların bazılarında yer bulan lesitin, vücut hücrelerinde gerekli olan bir fosfolipittir. Soya fasulyesi ve yumurta sarısı gibi birçok gıdada bulunur. İlaç üretiminde de kullanılan lesitin, bunama ve Alzheimer gibi hafiza bozuklukları, ayrıca safra kesesi, karaciğer hastalıkları bazı depresyon türleri, yüksek kolesterol ve egzama gibi çeşitli hastalıkların yardımcı (adjuvan) tedavisinde ilaç olarak kullanılmaktadır (19-22). Lesitinle yapılan kisitlı çalışmalar lesitinin yüzey aktif ajan özelliği nedeniyle bakterinin biyofilm oluşturması için yüzeye bağlanmasını engelleyebileceğini ortaya koymaktadır $(10,12,13)$. Aumeran ve ark. (12) yapmış oldukları bir çalışmada, 61 adet endoskop üzerinde oluşturulan Pseudomonas aeruginosa biyofilm tabakalarından örnek alınması sırasında bakterilerin uzaklaştırılması için \%0,7 lesitin+ $\% 0,5$ Tween 80 çözeltisinin tensiyoaktif özelliği nedeniyle tuzlu çözeltilere göre daha etkili olduğunu rapor etmişlerdir. Çalıșmamızda, lesitinle ilgili yapılan bu kısıtlı çalışmalardan elde edilen bulgular, lesitinin var olan biyofilme karşı etkili olabilecek uygun antibiyotiklerle birlikte kullanıldığında antibiyotiklerin biyofilme etki etmesiyle birlikte adjuvan gibi hareket ederek sinerjist etki ortaya koyabileceğini düşündürmüş ve bu alanda lesitinin kullanıldığı ilk çalışma olan araştırmamıza seçilmesine neden olmuştur.

$\mathrm{Bu}$ amaçla çalışmamızda, SVK biyofilm modeli oluşturularak lesitinin tek başına ve çeşitli antibiyotiklerle kombinasyon halinde AK çözeltisi olarak $K$. pneumoniae'ye karşı in vitro etkinliği araştırılmıştır.

Çalışmamızdan elde edilen bulgulara göre, tobramisin ve doripenemin tek başına 400xMIKK konsantrasyonlarında denendikleri koşullarda biyofilme gömülmüş $K$. pneumoniae hücre sayısında $>5 \log _{10}$ azalma sağlayarak kuvvetli bakterisidal etki göstermişlerdir $(\mathrm{P}<0,05)$.
Bununla birlikte lesitin ile tobramisin veya doripenemin kombinasyon halindeki etkilerini incelediğimiz çalışmalarmızda, her iki kombinasyonun da antibiyotiklerin tek başına olan etkisiyle karşılaştırıldığında biyofilmdeki bakteri sayısında $>2$ $\log _{10}$ artışa neden olarak NCCLS kriterleri doğrultusunda antagonist etki gösterdikleri tespit edilmiştir. Çalışmamızdan elde ettiğimiz bulgular, bir gıda takviyesi olarak sık kullanılan lesitinin fosfolipit bazlı organik bir yapı olması nedeniyle dezenfektanların proteinli ortamda aktivitesinin azalmasına benzer bir mekanizmayla antibiyotiklerle birlikte alındığında antibiyotklerin etkinliğini azaltabileceğini ortaya koyması açısından önemlidir.

Dirençli Gram negatif bakteri enfeksiyonlarına karş1 etkili bir terapötik ajan olarak kullanılan kolistinin AK çözeltisi olarak tek başına uygulandığı koşullarda $K$. pneumoniae biyofilmlerinde 48 . saatte bakteri sayısında önemli bir azalma sağlayarak bakterisidal $\left(>3 \quad \log _{10}\right)$ etkili olduğu görülmüş, ancak 72 . saatle birlikte bu örneklerde bakteri sayısında bir artış tespit edilmiştir. Kolsitinin lesitinle olan kombinasyonunun ise KP-2 suşu için 96. saatte kolistinin tek başına olan etkisiyle karşılaştırıldığında canlı bakteri sayısında $>2 \log _{10}$ artış sağlayarak antagonist etki gösterdiği saptanmıştır.

Çalışmamızda siprofloksasinin tek başına AK çözeltisi olarak denendiği koşullarda, siprofloksasine dirençli olan KP-1 suşuna karşı $>5 \log _{10}$ azalma sağlayarak kuvvetli bakterisidal etki gösterirken siprofloksasine duyarlı olan KP-2 için ise biyofilmdeki bakteri sayısında yaklaşık 2 $\log _{10}$ bir azalma sağladığı tespit edilmiştir. Benzer şekilde, Doreste ve arkadaşlarının (23) yapmış oldukları bir çalışmada düşük dozlarda siproflokasasin uygulamasının 7 günlük $P$. aeruginosa biyofilmlerinde herhangi bir etki gösteremediğini tespit etmişlerdir. $\mathrm{Bu}$ nedenle AK çözeltisi olarak siprofloksasinin kullanımı kateter ilişkili biyofilm enfeksiyon etkeni olarak biyofilme gömülü bakterinin türüne ve duyarlılığına bağlı olarak değişebilir. Lesitinin siprofloksasinle kombinasyon halinde uygulandığı çalışmalarımızdan elde ettiğimiz bulgulara göre ise siprofloksasin dirençli olan 
KP-1 suşunda bu kombinasyonun biyofilmdeki bakteri sayısında $1,5 \log _{10}$ artış sağladığı tespit edilmiştir.

Genişlemiş spektrumlu beta laktamaz üreten çoklu ilaç dirençli Gram negatif bakterilere karşı güçlü bir in vitro aktivite gösteren bakteriyostatik bir ajan olan tigesiklinin $(18,24)$ çalışmamızda 400xMIK konsantrasyonlarda tek başına denendiği koşullarda $K$. pneumoniae biyofilmlerinde $>\quad 3 \quad \log _{10}$ azalma sağladığ 1 tespit edilmiştir. Bununla birlikte lesitin ile tigesiklinin kombinasyon halinde etkisini incelediğimiz çalışmamızda diğer çalışılan antibiyotiklere benzer şekilde tigesiklinin tek başına olan etkisiyle kıyaslandığında biyofilmdeki bakteri sayısında denenen her iki suş için de yaklaşık 1,5 $\log _{10}$ artış gösterdiği tespit edilmiştir.

Çalışmamıza yüzey aktif madde özelliği ile biyofilm oluşumu için bakterinin yüzeye tutunmasını engelleyebilme kapasitesinin yanı sıra günümüzde sık kullanılan gida takviyelerinden biri olması sebebiyle dahil edilen lesitinin $(6,9,11)$ tek başına etkisini incelediğimiz çalışmalarımızda biyofilmdeki bakteri sayısına, kontrole benzer şekilde etkili olduğu görülmüştür. Buna karşılık, Kumon ve ark. (13) yapmış oldukları bir çalışmada lesitin, gümüş sitrat ve sıvı silikon karışımı ile kaplı yeni antibakteriyel kateterler geliştirilebileceğini savunmuş ve lesitinin bu kombinasyonda kateter yüzeyine hidrofilik bir yap1 kazandırarak bakterinin biyofilm yapısı kazanmak için yüzeye yapışmasını engelleyebileceğini öngörmüşlerdir. Ancak çalışmamızdan elde ettiğimiz biyofilme gömülü bakteri sayısına dayanan bulgular, lesitinin bakterinin kateter yüzeyine biyofilm oluşturmasında herhangi bir olumsuz etkisinin olmadığını göstermektedir.

\section{SONUÇ}

Çalışmamızda tobramisin ve doripenem K. pneumoniae biyofilmlerinin neden olduğu kateter biyofilmlerine karşı AK çözeltisi olarak güçlü bir bakterisidal ajan olarak tespit edilmiştir. Bununla birlikte, lesitin-antibiyotik etkileşimini inceleyen bu ilk çalışmadan elde edilen sonuçlarımız, hem gıda takviyesi hem de yardımcı ilaç olarak kullanılan lesitinin, çalıştığımız antibiyotiklerle kombinasyon halinde antagonist etki ortaya koyması bu ürünün antibiyotiklerle birlikte kullanımı konusunda uyarıcı verileri ortaya koymuştur.

\section{KAYNAKLAR}

1. Donlan RM. Biofilms on central venous catheters: is eradication possible? Curr Topics Microbiol Immunol. 2008; 322: 133-61.

2. Lee MY, Ko KS, Song JH. In vitro effectiveness of the antimicrobial lock technique (ALT) for the treatment of catheter-related infections by Pseudomonas aeruginosa and Klebsiella pneumoniae. J Antimicrob Chemother. 2007; 60(4): 782-7. https://doi.org/10.1093/jac/dkm295.

3. Costerton JW, Stewart PS, Greenberg EP. Bacterial biofilms: a common cause of persistent infections. Science. 1999; 284(5418): 1318-22. doi: 10.1126/science.284.5418.1318.

4. Mermel LA, Allon M, Bouza E, Craven DE, Flynn P, O’Grady NP, et al. Clinical practice guidelines for the diagnosis and management of intravascular catheter related infection: 2009 update by the infectious diseases society of America. IDSA Guidelines for intravascular catheter related infection. Clin Infect Dis. 2009; 49(1): 1-45. doi: 10.1086/599376.

5. Raad I, Hanna H, Dvorak T, Chaiban G, Hachem R. Optimal antimicrobial catheter lock solution, using different combinations of minocycline, EDTA, and 25-percent ethanol, rapidly eradicates organisms embedded in biofilm. Antimicrob Agents Chemother. 2007; 51(1): 78-83. doi:10.1128/AAC.00154-06.

6. Epa.gov [Internet]. Washington, DC, USA: US Environmental Protection Agency Office of Pesticide Programs, Office of Pesticide Programs Microbiology Laboratory Environmental Science Center, Ft. Meade, MD [Updated: 2016 Nov 08; Cited: 2019 Apr 5]. Available from: https://www.epa.gov/sites/production /files/2016-08/documents/mb-05-14.pdf.

7. Mataracı Kara E, Özbek Çelik B. Investigation of the effects of various antibiotics against Klebsiella pneumoniae biofilms on in vitro catheter model. Journal of Chemotherapy. 2018; 30(2): 82-8. doi: 10.1080/1120009X.2017.1390633.

8. Raad II, Hanna H, Maki D. Intravascular catheterrelated infections: advances in diagnosis, prevention, and management. Lancet Infect Dis. 2007; 7(10): 64557. https://doi.org/10.1016/S1473-3099(07)70235-9.

9. en-standard.eu [Internet]. Czech Republic: European Standard Store [Updated: 2018 May 15; Cited: 2019 Apr 5]. Available from: https://www.en-standard. eu/ 18-30373116-dc-bs-en-1276-chemical-disinfectantsand-antiseptics-quantitative-suspension-test-for-theevaluation-of-bactericidal-activity-of-chemicaldisinfectants-and-antiseptics-used-in-food-industrialdomestic-and-institutional-areas-test-method-and-re/.

10. Singh VK, Pandey PM, Agarwal T, Kumar D, Banerjee I, Anis A, et al. Development of soy lecithin based novel self-assembled emulsion hydrogels. J Mechanical Behavior of Biomedical Materials. 2016; 55: 250-63. doi: 10.1016/j.jmbbm.2015.10.027.

11. pharmacopeia.cn [Internet]. USA: The United States Pharmacopeia [Updated: 2008 May 15; Cited: 2019 Mar 1]. Available from: http://www.pharmacopeia.cn /v29240/ usp29nf24s0_c1227.html.

12. Aumeran C, Thibert E, Chapelle FA, Hennequin C, Lesens $\mathrm{O}$, Traore $\mathrm{O}$. Assessment on experimental bacterial biofilms and clinical practice of the efficacy of sampling solutions for microbiological testing of endoscopes. J Clin Microbiol. 2012; 50(3): 938-42. doi: 10.1128/JCM.06221-11.

13. Kumon H, Hashimoto H, Nishimura M, Monden K, Ono N. Catheter-associated urinary tract infections: impact of catheter materials on their management. Int J Antimicrob Agents. 2001; 17: 311-6. https://doi.org/10.1016/S0924-8579(00)00360-5.

14. eucast.org [Internet]. Basel Switzerland: European Society of Clinical Microbiology and Infectious Diseases [Updated: 2019 Jan 1; Cited: 2019 Apr 1]. Available from: http://www.eucast.org/fileadmin/src/media/PDFs/EU CAST_files/Breakpoint_tables/v_9.0_Breakpoint_Ta bles.pdf.

15. Stepanovic S, Vukovic D, Dakic I, Savic B, SvabicVlahovic M. A modified microtiter-plate test for quantification of staphylococcal biofilm formation. J 
Microbiol Methods. 2000; 40(2): 175-9. https://doi.org/10.1016/S0167-7012(00)00122-6.

16. clsi.org [Internet]. Wayne, PA: Clinical and Laboratory Standards Institute [Updated: 1999 Sep 1; Cited: 2019 Mar 1]. Available from: https://clsi.org/standards/products/microbiology/docu ments/m26/.

17. Justo JA, Bookstaver PB. Antibiotic lock therapy: review of technique and logistical challenges. Infect Drug Resist. 2014; 7: 343-63. doi: 10.2147/IDR.S51388.

18. Özbek Çelik B, Mataraci Kara E. Comparative in vitro efficacies of various antipseudomonal antibiotics based catheter lock solutions on eradication of Pseudomonas aeruginosa biofilms. J Chemother. 2016; 28(1): 20-4. https://doi.org/10.1179/ 1973947814Y.0000000212.11

19. Tudorache B, Lupulescu R, Dutan I, Sarbulescu A. Assessment of various psychopharmacological combinations in the treatment of presenile and senile primary degenerative dementia. Rom J Neurol Psychiatry. 1990; 28(4): 277-94.

20. Volz HP, Hehnke U, Hauke W. Improvement in quality of life in the elderly. Results of a placebocontrolled study on the efficacy and tolerability of lecithin fluid in patients with impaired cognitive functions. MMW Fortschr Med. 2014; 12-146(Suppl 3-4): 99-106.

21. Weintraub S, Mesulan MM, Auty R, Baratz R, Cholakos BN, Kapust L, et al. Lecithin in the treatment of Alzheimer's disease. Arch Neurol. 1983; 40(8): 527-8.

22. Wu Y, Wang T. Soybean lecithin fractionation and functionality. JAOCS. 2003; 80(4): 319-26.

23. Droste JC, Jeraj HA, MacDonald A, Farrington K. Stability and in vitro efficacy of antibiotic-heparin lock solutions potentially useful for treatment of central venous catheter related sepsis. J Antimicrob Chemother. 2003; 51(4): 849-55. https://doi.org/10. 1093 /jac/dkg179.

24. Aslam S, Trautner BW, Ramanathan V, Darouiche RO. Combination of tigecycline and $\mathrm{N}$-acetylcysteine reduces biofilm-embedded bacteria on vascular catheters. Antimicrob Agents Chemother. 2007; 51(4): 1556-68. doi: 10.1128/AAC.00893-06. 